\title{
Dynamic Modeling and Performance Analysis of PMSG- based Variable Speed WTG: Case Study of Adama Wind Farm I, Ethiopia
}

\section{Zenachew Muluneh* and Gebremichael Teame}

School of Electrical and Computer Engineering, Ethiopian Institute of Technology [EIT - M] Mekelle University, Ethiopia (*zenachew.muluneh@mu.edu.et).

\begin{abstract}
In this paper, the performance of Permanent Magnet Synchronous Generator (PMSG) -based Variable Speed Wind Turbine Generator (WTG) at Adama Wind Farm I (WTG), connected to a grid is studied. To study the performance of the WTG, both machine and grid side converters are modeled and analyzed very well. On the machine side, maximum power point tracking (MPPT) for maximum energy extraction is done using the direct speed control (DSC) technique, which is linked with the optimal tip speed ratio for each wind speed value considered. On the grid side, dc-link voltage and reactive power flow to the grid are controlled. For this purpose, first, the simulation model of the system is prepared in MATLAB Simulink considering the dynamic mathematical model of the PMSG, and Wind Turbine Aerodynamic model using the user-defined function blocks. Then, the PI regulators designed for direct speed, torque (current) control, and dc-link voltage are employed in the model. Moreover, to study and analyze the behavior of the system in a variable speed operation, a wind speed starting from cut-in wind speed $(3 \mathrm{~m} / \mathrm{s})$ to the rated wind speed $(11 \mathrm{~m} / \mathrm{s})$ is applied in $4 \mathrm{~s}$. The simulation result of the existing system model shows that the actual values of performance variables correspond well with the analytical values of the system. In addition, the chosen control algorithms applied in the control system of the generator-side converter are hence verified.
\end{abstract}

Keywords: Wind energy, PMSG, WTG, dc-link control, MATLAB-Simulink, Adama Wind Farm I, Ethiopia.

\section{INTRODUCTION}

Ethiopia has around $4238 \mathrm{MW}$ installed power generation capacity. Out of which, about $90 \%$ (3807 MW) is from hydroelectric power and about 7.65\% (324 MW) is from wind energy. Wind energy is significantly low even though the total predicted energy from wind is around 10000 MW (Ethiopian Electric Power, 2020). One of the reasons for this is the limited focus on this energy which is well reflected in the limited studies on the existing wind farms. Moreover, the wind turbine generator manufactures are reluctant to provide detail technical information regarding the already installed Wind Turbine Generators (WTG). So, there is a need to undertake more researches on the performance of the existing system to encourage and increase the installation of more wind farms in the country. The existing wind farms in Ethiopia have variable speed wind energy conversion systems, due to this reason, variable speed dominant over fixed speed wind energy conversion systems for their ability to track maximum power (MPPT) to extract maximum power at variable wind speed with higher overall 
efficiency, power quality and their ability to be controlled to reduce aerodynamic noise and mechanical stress on the WTG (Wu et al., 2011; Ackermann, 2012; Abu-Rub et al., 2014).

Variable speed WTGs operate at a variable speed to achieve maximum energy conversion in a wide range of wind speed. For this purpose, the WTGs will continuously adjust their speed according to the wind speed in order to keep the tip speed ratio optimal and achieve the maximum possible energy conversion efficiency (Wu et al., 2011; Ackermann, 2012; AbuRub et al., 2014). Permanent magnet synchronous generator (PMSG)- based WTG is one of the variable speed WTGs which uses full -scale back-to-back converter connected between the generator and a grid to control the active and reactive power of the generator according to the maximum power point tracking, and the dc-link voltage and reactive power flow to the grid (Wu et al., 2011; Polinder et al., 2013; Abu-Rub et al., 2014). Three different schemes are basically used for controlling the torque or power of PMSG-based WTGs, i) zero d-axis current control (ZDC), ii) maximum torque per ampere control (MTPA), and iii) unity power factor control (UPF) (Wu et al., 2011).

ZDC and MTPA control scheme are used for both non -salient and salient pole PMSGbased WTG. However, ZDC is generally recommended for non-salient pole PMSG-based WTG and UPF scheme which has limited operating range. Moreover, three control schemes are usually used to perform the maximum power point tracking (MPPT), which are MPPT with turbine profile picture, with optimal tip speed ratio and with optimal torque control (Wu et al., 2011).

In this paper, MPPT with optimal tip speed ratio and ZDC scheme control (since the generator used in the wind farm is non-salient pole type) technique are considered to model and study the performance of the grid connected PMSG- based WTG of Adama Wind farm I.

\section{METHODOLOGY}

\subsection{Wind Turbine Generator (WTG) Data}

Under this section, WTG data's of Adama Wind Farm-I given in appendix 1 and 2 are used to design the PI regulator of the controllers of the system and prepare the dynamic model of the system.

\subsection{Modeling of the System}

\subsubsection{Modelling of the Machine}

Mathematical modeling of the permanent magnet synchronous machine (PMSM) which is important for preparing the simulation model of the system, designing the PI regulator for controlling speed, and current of the WTG as well as analyze transient and steady-state 
characteristics of the PMSG- based WTG, is presented below. Dynamic modelling of the machine is derived from the stator voltage equation of the machine in its natural ABC threephase stationary reference frame (equation 1) (Krause et al., 2013).

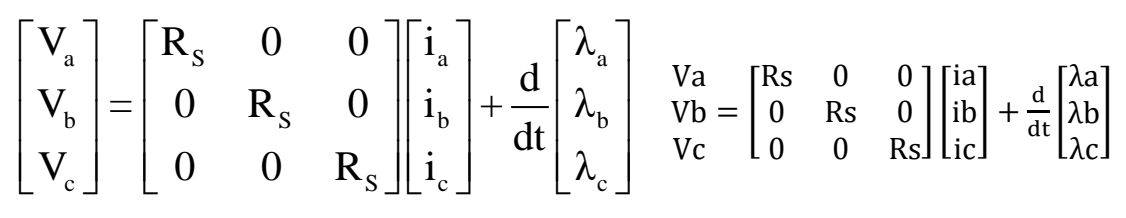

Where,

Rs is the per phase resistance of the stator winding in $\Omega, \mathrm{V}_{\mathrm{a}}, \mathrm{V}_{\mathrm{b}}, \mathrm{V}_{\mathrm{c}}$ and $\mathrm{i}_{\mathrm{a}}, \mathrm{i}_{\mathrm{b}}, \mathrm{i}_{\mathrm{c}}$ are the instantaneous per phase stator voltages and currents in (V) and (A) and, $\lambda_{\mathrm{a}}, \lambda_{\mathrm{b}}, \lambda_{\mathrm{c}}$, are the instantaneous flux linkages induced by the three-phase $\mathrm{AC}$ currents in $(\mathrm{Wb})$.

And the expression for the instantaneous flux linkage is given below (Krause et al., 2013).

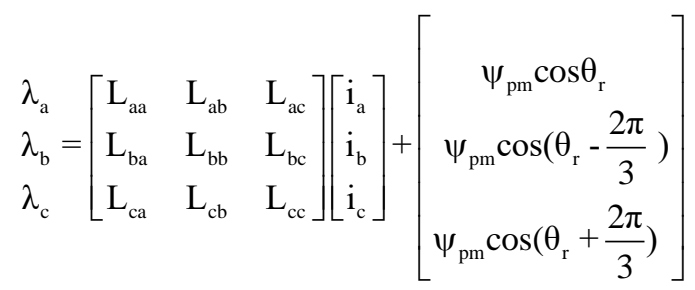

Where,

$\psi_{\mathrm{pm}}$ is flux linkages of the permanent magnet rotor of the PMSM; and L is the inductance of the stator winding.

Clark transformation is applied on equations 1,2 and 3 to transform the terminal voltage equation of the machine from its natural three-phase coordinate $A-B-C$ to their equivalent $\alpha-\beta$ 0 stationary reference frame as shown in equation 3.

$$
\mathrm{V}^{\mathrm{S}}=\mathrm{Ri}^{\mathrm{S}}+\mathrm{L} \frac{\mathrm{di}^{\mathrm{S}}}{\mathrm{dt}}+\psi_{\mathrm{pm}} \omega_{\mathrm{e}}\left[\begin{array}{c}
-\sin \theta \\
\cos \theta
\end{array}\right]
$$

Determined the expression for stator terminal voltage of salient pole PMSM with Ld, and Lqinductance in the dq0 rotating frame, applied again Park transformation on equation 3,

$$
\begin{aligned}
& \mathrm{V}_{\mathrm{d}}=\mathrm{Ri}_{\mathrm{d}}+\mathrm{L}_{\mathrm{d}} \frac{\mathrm{di} \mathrm{d}_{\mathrm{d}}}{\mathrm{dt}}-\mathrm{L}_{\mathrm{q}} \mathrm{i}_{\mathrm{q}} \omega_{\mathrm{e}} \\
& \mathrm{V}_{\mathrm{q}}=\mathrm{Ri}_{\mathrm{q}}+\mathrm{L}_{\mathrm{q}} \frac{\mathrm{di}_{\mathrm{q}}}{\mathrm{dt}}+\mathrm{L}_{\mathrm{d}} \mathrm{i}_{\mathrm{d}} \omega_{\mathrm{e}}+\psi_{\mathrm{pm}} \omega_{\mathrm{e}}
\end{aligned}
$$


Finally, the active and reactive power of the machine at $\alpha-\beta-0$ stationary reference frame and d-q-0 synchronously rotating reference is determined using the equations given below ( $\mathrm{Wu}$ et al., 2011, Abu-Rub et al., 2014).

$$
\begin{aligned}
& \mathrm{P}_{\alpha \beta}=\frac{3}{2}\left(\mathrm{~V}_{\alpha} \mathrm{i}_{\alpha}+\mathrm{V}_{\beta} \mathrm{i}_{\beta}\right) \\
& \mathrm{P}_{\mathrm{dq}}=\frac{3}{2}\left(\mathrm{~V}_{\mathrm{d}} \mathrm{i}_{\mathrm{d}}+\mathrm{V}_{\mathrm{q}} \mathrm{i}_{\mathrm{q}}\right) \\
& \mathrm{Q}_{\alpha \beta}=\frac{3}{2}\left(\mathrm{~V}_{\alpha} \mathrm{i}_{\beta}-\mathrm{V}_{\beta} \mathrm{i}_{\alpha}\right) \\
& \mathrm{Q}_{\mathrm{dq}}=\frac{3}{2}\left(\mathrm{~V}_{\mathrm{d}} \mathrm{i}_{\mathrm{q}}-\mathrm{V}_{\mathrm{q}} \mathrm{i}_{\mathrm{d}}\right)
\end{aligned}
$$

\subsubsection{Modelling of the Wind Turbine}

The wind stream, which passes over the blades, causes a turning force over a shaft inside the nacelle. The kinetic energy of an air mass of wind with a total mass, m, moving at a wind velocity, $\mathrm{V}_{\mathrm{w}}$, crossing a swept area (A) is given by equation 6 (Wu et al., 2011; Abad et al., 2011; Ackermann, 2012; Abu-Rub et al., 2014).

$$
\mathrm{E}=\frac{1}{2} \mathrm{mVw} \mathrm{w}^{2}
$$

If, $\mathrm{m}$ is weight of air particles moving at a speed $\mathrm{V}_{\mathrm{M}}$, for a period of time $\mathrm{t}$ as given by equation 7 is substituted on equation 6 and is rewritten as below.

$$
\begin{aligned}
& \mathrm{m}=\rho \mathrm{AVw} \\
& \mathrm{p}=\frac{1}{2} \rho A \mathrm{Vw}^{3}
\end{aligned}
$$

Where, $\rho$ is the air density, and $\mathrm{A}$ is the swept area equivalent.

Only a portion of the power in the air can be recovered by a wind turbine, for this reason the power coefficient $(\mathrm{Cp})$ is considered to represent a conversion efficiency of a wind turbine (Abad et al., 2011). Finally, the wind power captured by the blade and converted into mechanical power is calculated using the below equation.

$$
\mathrm{p}=\frac{1}{2} \rho \pi R^{2} \mathrm{Vw}^{3} C_{p}
$$

Where, $\mathrm{R}$ is the radius of wind turbine.

A wind turbine characterized by its aerodynamic power is represented by equation 10 (Abad et al., 2011). 


$$
\mathrm{p}=\frac{1}{2} \rho \pi R^{2} \mathrm{Vw}^{3} C_{p}(\theta, \lambda)
$$

Where, $\Theta$ is the pitch angle in degrees, and $\lambda$ is the tip speed ratio.

The tip speed ratio $(\lambda)$ is given by equation 11 (Wu et al., 2011; Abad et al., 2011; Ackermann, 2012; Abu-Rub et al., 2014).

$$
\lambda=\frac{\omega \mathrm{tR}}{\mathrm{Vw}}
$$

From equation 10, the maximum power is extracted by varying the turbine speed with wind speed in case of turbine modeling is for maximum power tracking. So that it is on the track of the maximum power curve at all times. The optimum power (Popt) is expressed as below (equation 12) at a pitching angle $\Theta=0$ :

$$
\mathrm{p}=\frac{1}{2} \rho \pi R^{5} \frac{C_{p \max }}{\lambda_{\text {opt }}{ }^{3}}\left(\theta=0, \lambda_{\text {opt }}\right) w t^{3}
$$

\subsubsection{Modelling of the dc-link}

The dc side of the back to back converter is commonly called the dc-link. It stores a certain amount of energy in the capacitors (Abad, 2016). The dc-link model usually describes the dclink capacitor voltage variations as a function of the input power to the dc- link.

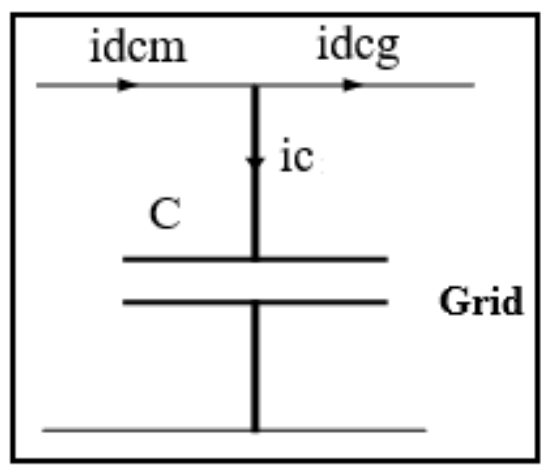

Figure 1. Simplified model of a dc-link.

The dc voltage dependent on the current through the capacitor is given by the following (Monica et al., 2006).

$$
\begin{gathered}
\mathrm{Ic}=\mathrm{C} \frac{\mathrm{dVdc}}{\mathrm{dt}} \\
\mathrm{Ic}=\mathrm{Idcm}-\mathrm{Idcg}
\end{gathered}
$$




\subsubsection{Modelling of the Filter}

To study the grid side operation performance of the grid connected WTG the filter and grid modelling are very important. The grid side filter is connected to between the grid and grid side converter. The objective of this filter is to minimize the current and voltage harmonics generated by the switching of the converter (Abad, 2016). Owing to the different characteristics of the converters, various filter topologies as such the inductive $\left(\mathrm{L}_{\mathrm{f}}\right)$ and the LCL filter is used. For this study, an inductive filter with an accompanied and an unavoidable resistance $\left(\mathrm{R}_{\mathrm{f}}\right)$ is considered in the modeling and simulation (Berhanu et al., 2018).

$$
\begin{array}{r}
\mathrm{Uai}=\mathrm{R}_{\mathrm{f}} \mathrm{iga}+\mathrm{L}_{\mathrm{f}} \frac{\mathrm{di}_{\mathrm{f}}}{\mathrm{dt}}+\mathrm{Uga} \\
\mathrm{Ubi}=\mathrm{R}_{\mathrm{f}} \mathrm{igb}+\mathrm{L}_{\mathrm{f}} \frac{\mathrm{di}_{\mathrm{f}}}{\mathrm{dt}}+\mathrm{Ugb}
\end{array}
$$

Where, Uai, Ubi, Uga and Ugb are inverter and grid voltages in their $\alpha-\beta-0$ stationary reference.

\subsection{Control of PMSG-based WTG}

In general, variable speed wind turbine is controlled in three different levels. Level one and two are mainly focused in this present study which deals with the regulation of power flow between the grid including the wind turbine control issues such as MPPT control and pitch control. Level three, in general, is the wind farm control level, which is not in the scope of the present work (Wu et al., 2011; Abad, 2016).

In drives, consequently also in wind turbine technology, control plays a very important role. Control of the permanent magnet generators while generating energy in wind turbine is very important and unavoidable. It maintains magnitudes of the generator such as torque, active and reactive power, and magnitudes related to the grid side converter such as reactive power and dc-link voltage close to their optimum values for proper and effective energy generation (Wu et al., 2011; Teodorescu et al., 2011; Abu-Rub et al., 2012; Jayalakshmi et al., 2012).

Vector control is a very common and powerful method to control brushless ac drives. It is also known as field orientated control (FOC). The FOC approach has been and continues to be a significant factor in PMSMs control. It makes it possible that PMSMs can be controlled as easily as dc machines. In general, FOC is a technique to decouple machine flux linkage and torque, to produce fast torque response and high energy conversion rates. In which, the machine torque is controlled indirectly by iqs, the torque-producing stator current component as shown by equation 19 and the flux is controlled by ids, flux-producing stator current component which 
is equal to ids. Thus, the dq-axes currents can be controlled independently by two closed loop controls in the FOC approach of PMSG (Wu et al., 2011).

For implementing FOC, the terminal voltage equations of PMSG in its d-q-0 synchronously rotating reference frame are considered and d-axis current component is kept zero as the rotor of PMSM is a permanent magnet, so that the stator current $i_{\mathrm{s}}$ will be equivalent to iqs, accordingly equation 5 is modified to derive electromagnetic torque (Te).

$$
\mathrm{P}_{\mathrm{em}}=\frac{3}{2}\left(\mathrm{e}_{\mathrm{d}} \mathrm{i}_{\mathrm{d}}+\mathrm{e}_{\mathrm{q}} \mathrm{i}_{\mathrm{q}}\right)
$$

Where,

ed and eq are the back EMFs of the PMSG (Zenachew et al., 2019a and 2019b).

$$
\begin{aligned}
& \mathrm{e}_{\mathrm{q}}=\mathrm{L}_{\mathrm{d}} \mathrm{i}_{\mathrm{d}} \omega_{\mathrm{e}}+\psi_{\mathrm{pm}} \omega_{\mathrm{e}}=\lambda_{\mathrm{d}} \omega_{\mathrm{e}} \\
& \mathrm{e}_{\mathrm{d}}=-\mathrm{L}_{\mathrm{d}} \mathrm{i}_{\mathrm{q}} \omega_{\mathrm{e}}=-\lambda_{\mathrm{q}} \omega_{\mathrm{e}}
\end{aligned}
$$

And the electromagnetic torque is derived from equation 17 and 18.

$$
\begin{aligned}
& \mathrm{T}_{\mathrm{em}}=\frac{3}{2} \mathrm{~N}_{\mathrm{p}}\left(\psi_{\mathrm{pm}} \mathrm{i}_{\mathrm{q}}+\left(\mathrm{L}_{\mathrm{d}}-\mathrm{L}_{\mathrm{d}}\right) \mathrm{i}_{\mathrm{q}} \mathrm{i}_{\mathrm{d}}\right) \\
& \mathbf{T t}=\mathbf{T}_{\mathrm{em}}=\frac{3}{2} \mathrm{~N}_{\mathrm{p}} \Psi_{\mathrm{pm}_{\mathrm{q}}} \mathrm{i}_{\mathrm{q}}
\end{aligned}
$$

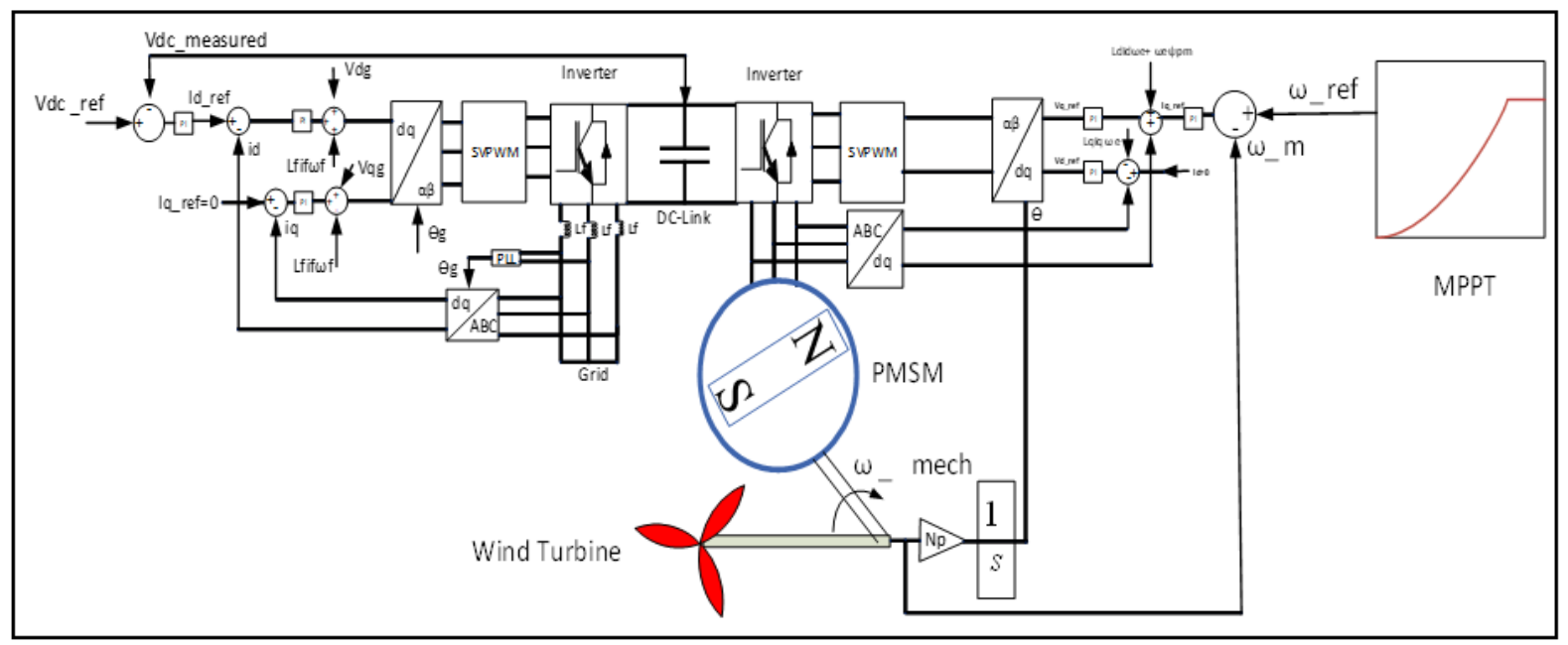

Figure 2. Schematic Diagram of the System.

\subsubsection{Inner Current Loop PI Current Controller Design}

The design of PI current controller of the system starts from the stator voltage equations of the PMSM in d-q- 0 reference given by equation 4 to determine the transfer function of the plant. While deriving the transfer function, from equation 4 , the back-emf common terms of the two equations is subtracted in order to easily derive the transfer function and control the two currents $i_{q}$ and $i_{d}$ independently, moreover, this simplifies the transfer function of the PMSM 
for tuning the PI current controllers. The transfer function of the PMSM after applying Laplace transform on equation 4 is given below. Since the transfer function of both equations is the same, the explanation will be represented by the transfer function of $\mathrm{i}_{\mathrm{q}}$ current.

$$
\frac{\mathrm{i}_{\mathrm{q}}(\mathrm{s})}{\mathrm{V}_{\mathrm{q}}(\mathrm{s})}=\frac{1}{\mathrm{R}+\mathrm{L}_{\mathrm{q}} \mathrm{s}}
$$

In the present study, for tuning and calculating the proportional gains of PI regulator ( $\mathrm{K}_{\mathrm{pi}}$ and $\mathrm{K}_{\mathrm{ii}}$ ) of inner loop current controller of optimal modulus $(\mathrm{OM})$ criterion is used (AbuRub et al., 2014; Teodorescu et al., 2011; Franklin et al., 2009).

$$
\begin{gathered}
\mathrm{K}_{\mathrm{pi}}+\mathrm{K}_{\mathrm{ii}} \frac{1}{\mathrm{~s}}=\mathrm{K}_{\mathrm{pi}} \frac{\mathrm{T}_{\mathrm{ii}} \mathrm{s}+1}{\mathrm{~T}_{\mathrm{ii}} \mathrm{s}} \\
\mathrm{T}_{\mathrm{ii}}=\frac{\mathrm{K}_{\mathrm{pi}}}{\mathrm{K}_{\mathrm{ii}}} \\
\mathrm{T}_{\mathrm{ii}}=\mathrm{T}_{\mathrm{m}}
\end{gathered}
$$

The PI current controller proportional gain is calculated using the optimal modulus $(\mathrm{OM})$ criterion considering a damping factor $\zeta=\sqrt{2} / 2$ for critical damping and approximating $\mathrm{T}_{\text {disum }}$ to 1.5 times Ts (Sampling time) (Zenachew et al., 2019a and 2019b).

$$
\mathrm{K}_{\mathrm{pi}}=\frac{\mathrm{T}_{\mathrm{ii}} \mathrm{R}}{4 \mathrm{~T}_{\text {disum }} \zeta^{2}}
$$

\subsubsection{Outer Loop PI Speed Controller Design}

For designing of PI speed controller of the system, the expression for the transfer function of the plant is derived from the mechanical equation of the PMSM to calculate the mechanical speed of the machine. Given below is the equation for calculating the mechanical speed of the machine (Zenachew et al., 2019b).

$$
J \frac{d \omega_{m}}{d t}=T_{e}-T_{L}+\omega_{m} B
$$

Where,

$\mathrm{T}_{\mathrm{e}}$ is electromagnetic torque of PMSM given by equation 20 (Wu et al., 2011; Abad et al., 2011; Yaramasu and Wu, 2014; Orlando et al., 2013; Deng et al., 2017).

Viscous friction coefficient (B) is very small. For this reason it is ignored while designing the PI speed controller. After Laplace transform on equation 24, the transfer function for mechanical speed becomes:

$$
\omega_{m}=\frac{T_{e}-T_{L}}{J_{S}}
$$


For developing the speed control loop of the system, a delay is introduced by the digital calculation for speed with time constant $\mathrm{T}_{\mathrm{ds}}$; delay introduced by the filters for the measured speed with time constant $\mathrm{T}_{\mathrm{f}}$; and the delay of the inner current control loop with time constant of $\mathrm{T}_{\text {eqi }}$ represented by a first order transfer function, are considered for tuning PI speed regulator gains. The delay of the inner current control loop is twice the overall sum of delay time considered in the inner loop, $\mathrm{T}_{\text {eqi }}=2 \mathrm{~T}_{\text {disum, }}$ (Abu-Rub et al., 2014; Zenachew et al., 2019b).

$$
\begin{gathered}
\mathrm{T}_{\text {eqi }}=2 \mathrm{~T}_{\text {disum }} \\
\mathrm{T}_{\mathrm{dsum}}=\mathrm{T}_{\mathrm{ds}}+\mathrm{T}_{\mathrm{f}}+\mathrm{T}_{\text {ieq }}
\end{gathered}
$$

For transfer function scenario with a double integration when the controller is included, the symmetrical optimum method is the standard design procedure recommended for tuning the PI controllers. For this purpose, symmetrical optimum method is used for calculating the PI speed gains using the following equations (Teodorescu et al., 2011; Zenachew et al., 2019b).

$$
\begin{aligned}
& \mathrm{K}_{\mathrm{p}}=\frac{1}{2 \mathrm{~K}_{1} \mathrm{~T}_{1}} \\
& \mathrm{~T}_{\mathrm{i}}=4 \mathrm{~T}_{1}
\end{aligned}
$$

Therefore, the gains and integral time of the PI speed controller will become,

$$
\begin{aligned}
& \mathrm{K}_{\mathrm{ps}}=\frac{\mathrm{J}}{2 \mathrm{~K}_{\mathrm{c}} \mathrm{T}_{\mathrm{dsum}}} \\
& \mathrm{T}_{\mathrm{is}}=4 \mathrm{~T}_{\mathrm{dsum}}
\end{aligned}
$$

Where, $\mathrm{K}_{\mathrm{C}}=\frac{3 \mathrm{~N}_{\mathrm{p}} \psi_{\mathrm{pm}}}{2}$

In this study, an angular acceleration in $\mathrm{rad} / \mathrm{s}^{2} \mathrm{~A}$ is measured after $500 \mathrm{~A}$ step iq current test on the system as shown in figure 4 is used instead of the value of $\mathrm{K}_{1}=\mathrm{K}_{\mathrm{C}} / \mathrm{J}$ in equation 28 .

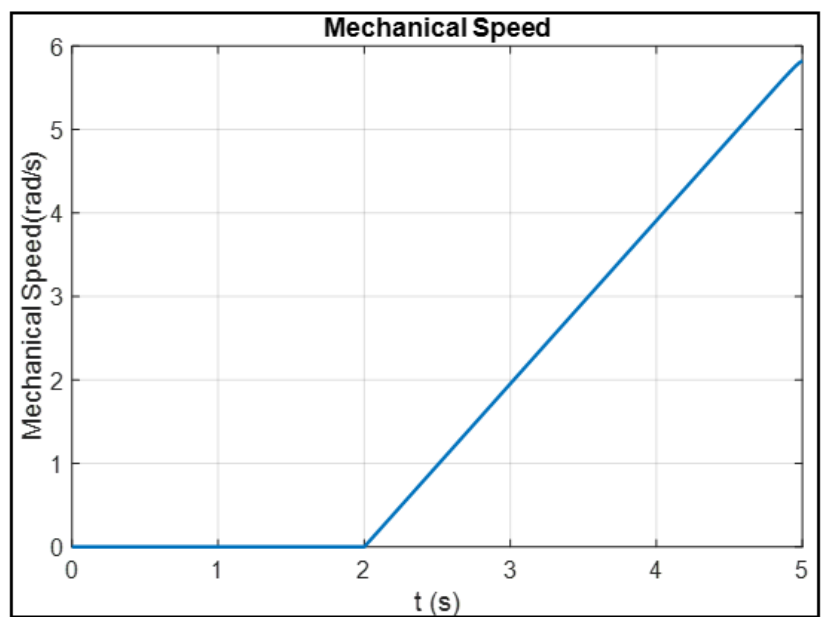

Figure 3. Measured Mechanical speed at 500A step iq current. 


\section{SIMULATION RESULT AND DISCUSSION}

The model of the system is prepared in MATLAB-Simulink to validate and explore the control performance of the chosen case study system. Figure 4 shows the model of the overall system built in Simulink, and figures 5 to 12, show simulation results of the proposed system related to the machines and grid side control.

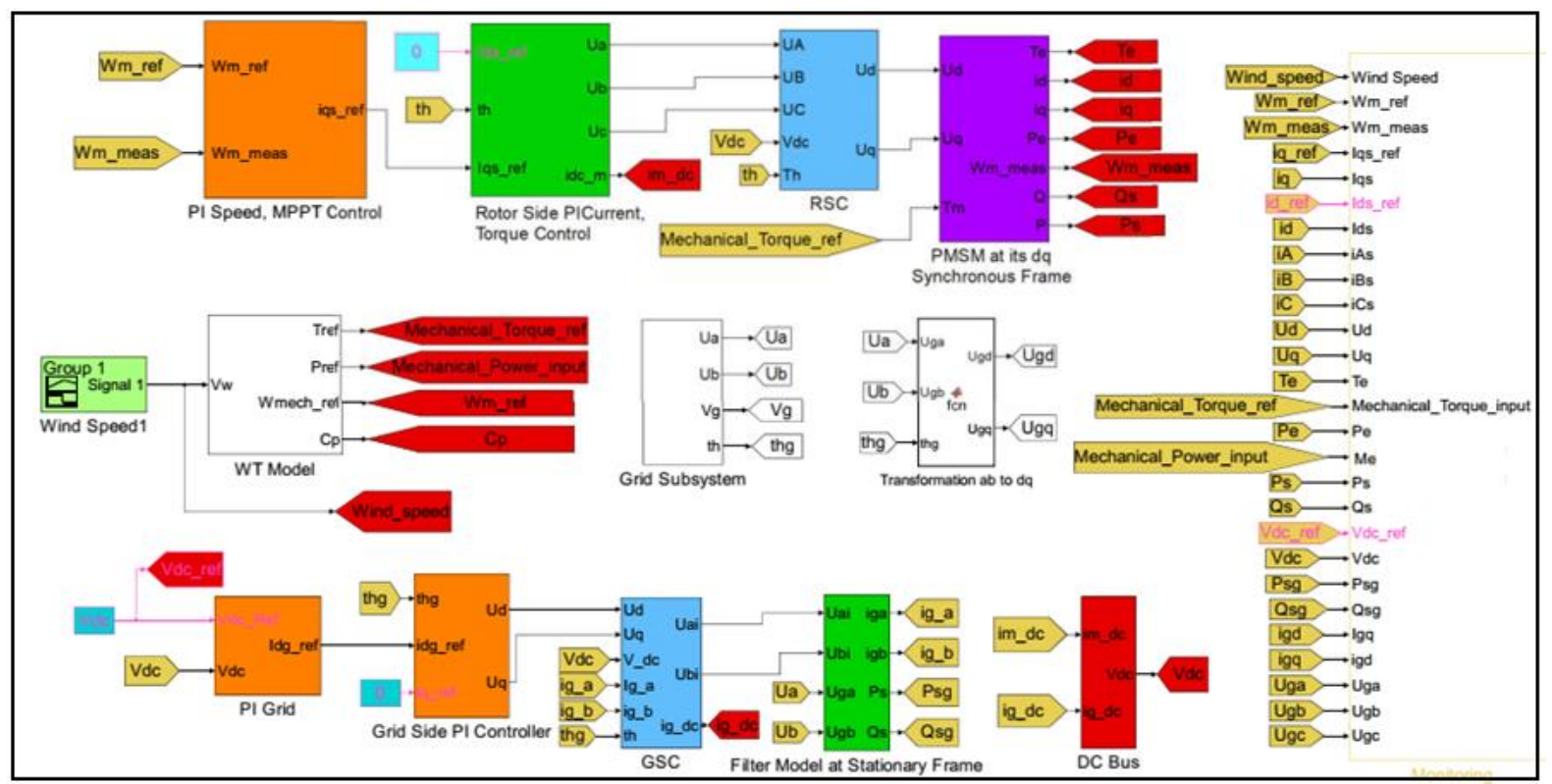

Figure 4. Simulation model of the system in MATLAB Simulink.

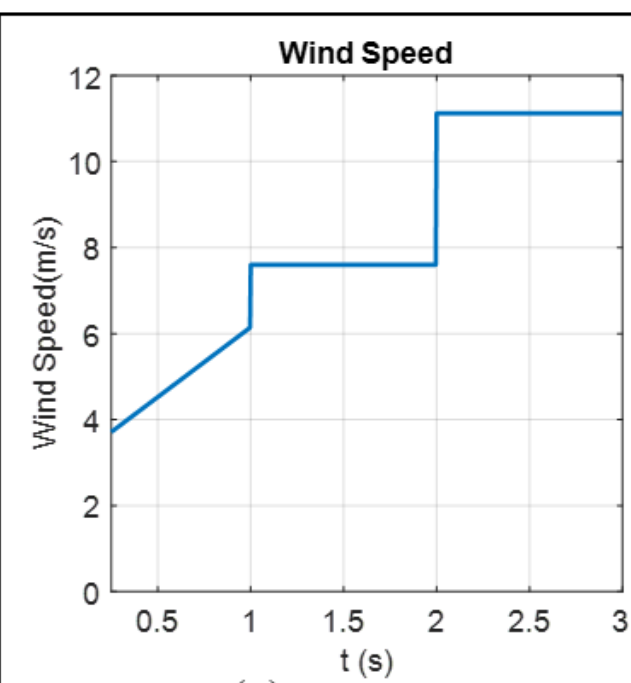

(a)

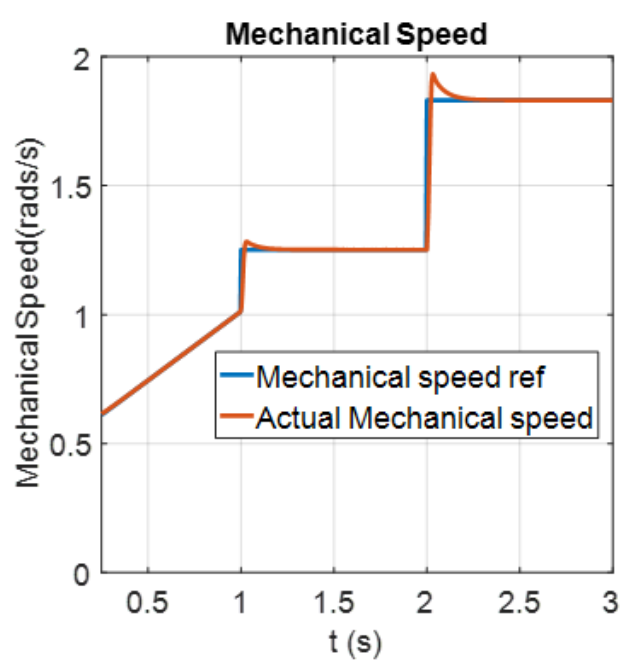

(b)

Figure 5. (a) Wind speed supplied to WTG (a); (b) actual mechanical and mechanical speed ref of the WTG.

Figure 5 (a) presents the applied wind speed to the system. As it is shown from the figure, the wind speed ramp from $3 \mathrm{~m} / \mathrm{s}$ (cut-in speed) to $6 \mathrm{~m} / \mathrm{s}$ and step up to $7.45 \mathrm{~m} / \mathrm{s}$ then maintained at this speed for 1s. At this wind speed, the steady state performance of the proposed 
MPPT control strategy is investigated. Then the wind speed is again step up to $11 \mathrm{~m} / \mathrm{s}$ (rated wind speed) to evaluate the steady state performance of the system at rated wind speed condition. Figure 5(b) shows rotational speed of the PMSG regulated to keep tip-speed ratio and achieve MPPT.

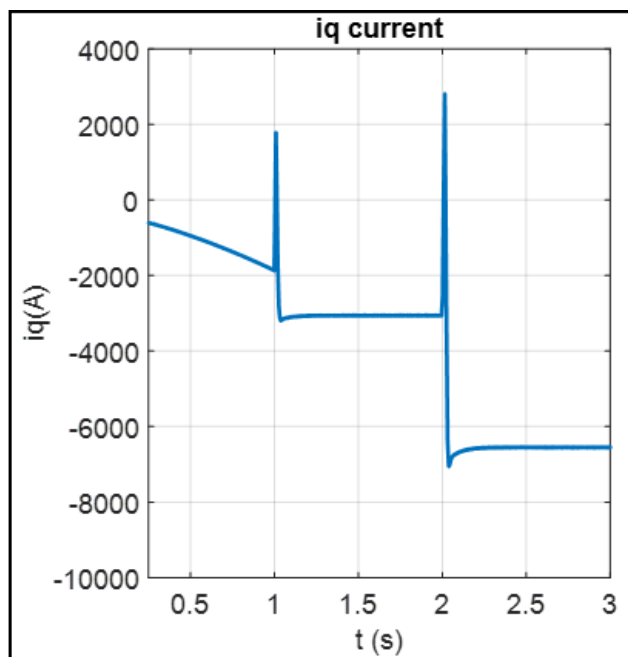

(a)

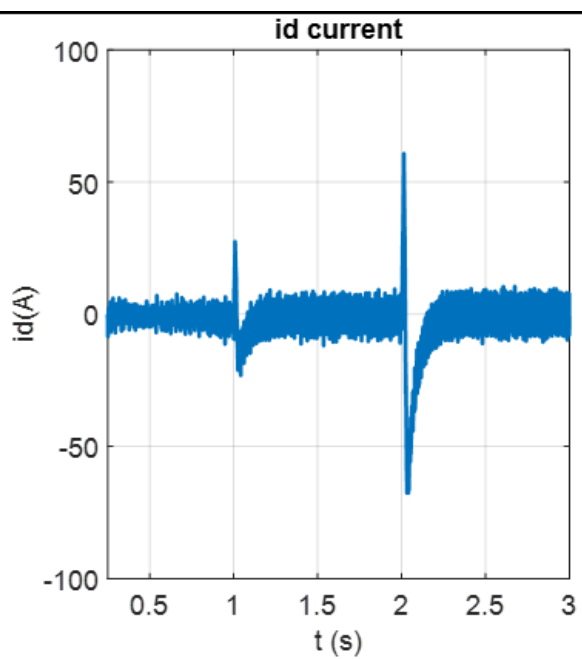

(b)

Figure 6. (a) Actual iqs, current of stator; and (b) actual ids, current of stator.

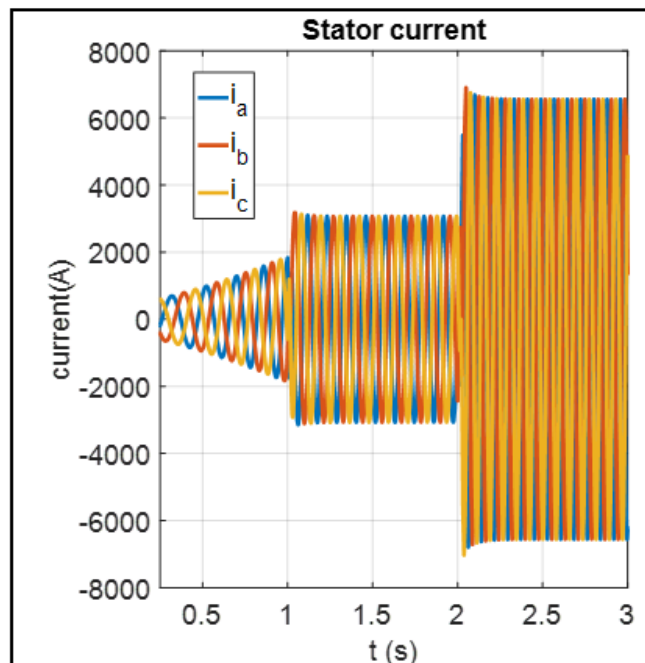

(a)

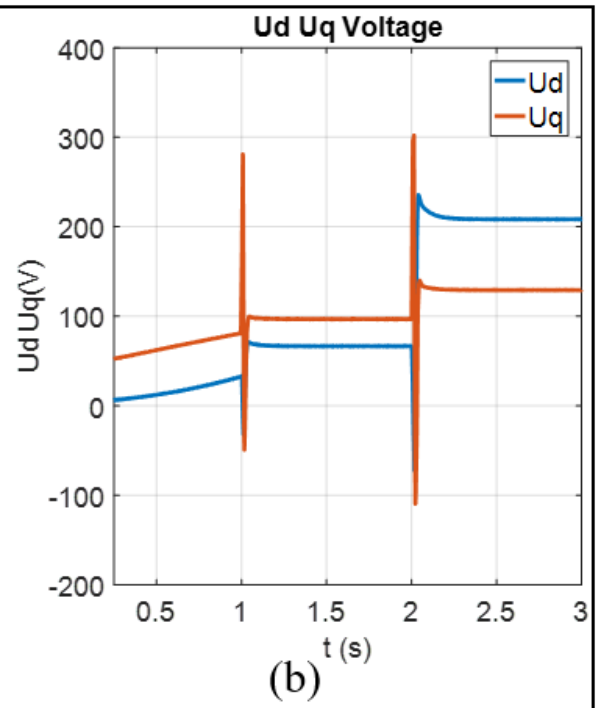

(b)

Figure 7. (a) Three phase stator current of stator; and (b) Ud, Uq voltage of the stator.

Figures 7 and 8 show the actual stator currents in $\mathrm{dq} 0$ as well as $\mathrm{ABC}$ frame and actual stator voltage in $\mathrm{dq0}$ frame. From the result it is clearly shown that iqs (q-axis current) is directly related to electromagnetic torque as it is presented in equation 8 and it is shown that the d-axis current is controlled to be zero, which contributes to a linear relationship between the q-axis current and the electromagnetic torque. 


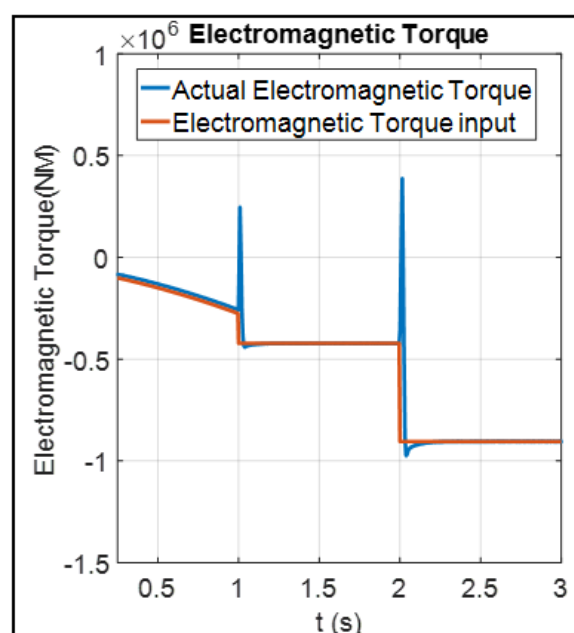

(a)

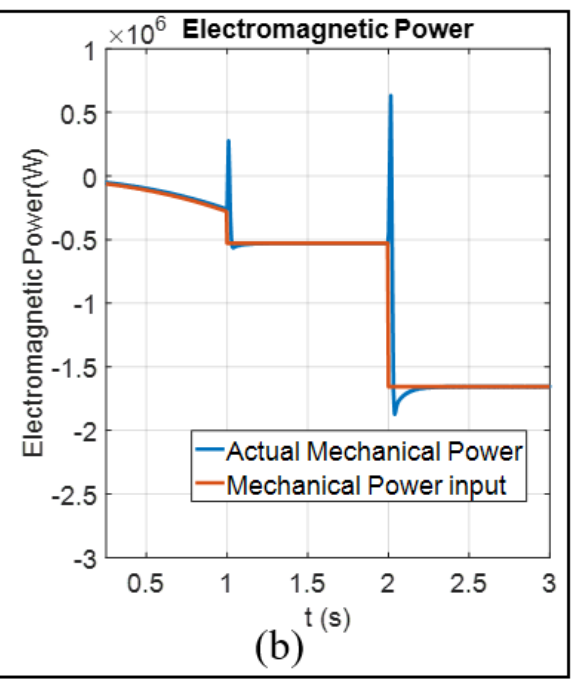

Figure 8. (a) Electromagnetic torque input, actual electromagnetic torque of the machine; and (b) actual mechanical power and mechanical power input.

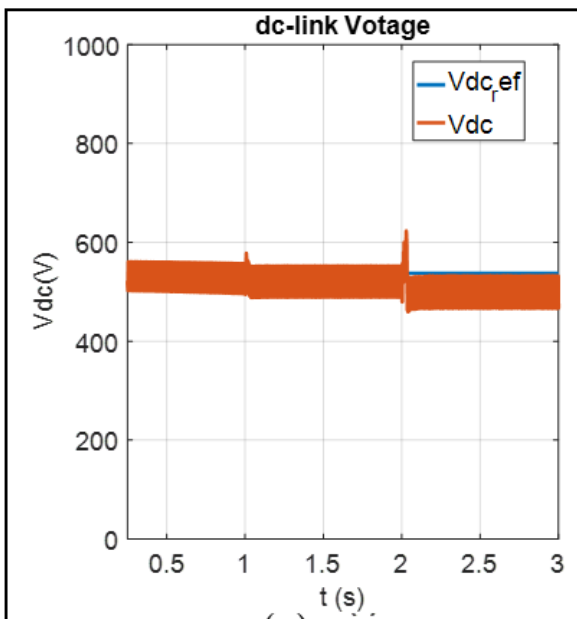

(a)

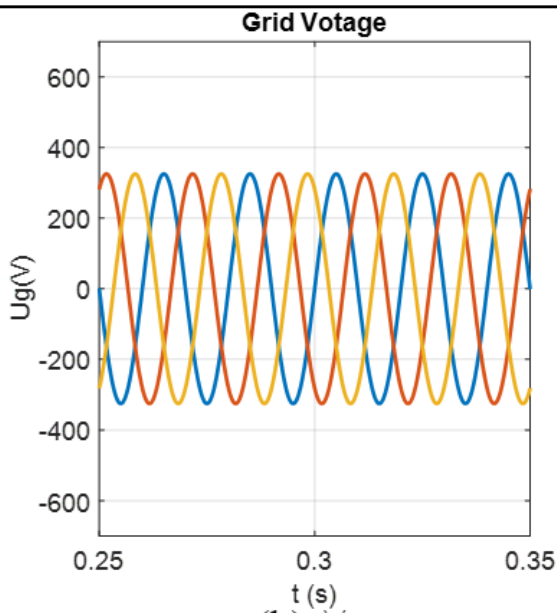

(b)

Figure 9. (a) Reference dc-link voltage, actual dc-link voltage; and (b) grid voltage.

Figure 9 shows the actual and reference or input electromagnetic torque and power of the generator. From the result it is clearly shown that the reference electromagnetic torque and power are tracked very well except the small over shoot for a very short time, which indicates that the MPPT control is applied very well in the system.

The simulation result is compared with the analysis result of the system to study the performance of the simulation model of the actual system. The reference mechanical generator speed in radians per second at steady state wind speed $(7.45 \mathrm{~m} / \mathrm{s})$ is calculated based on equation 11 and given below.

$$
\omega \mathrm{t}=\frac{6.14 * 7.45}{37.2}=1.23 \mathrm{rad} / \mathrm{s}
$$


The mechanical power captured by the wind turbine based on equation 12 is:

$$
\mathrm{p}_{\mathrm{t}}=\frac{1}{2} * 1.22 * \pi * 37.2^{2} * 0.45 *\left(\theta=0, \lambda_{\text {opt }}\right) * 7.45^{3}=.4934 * 10^{6} \mathrm{~W}
$$

The mechanical torque on the rotor shaft is calculated using the following formula (Abad et al., 2011).

$$
\begin{gathered}
\mathrm{T}_{\mathrm{t}}=\frac{\mathrm{Pt}}{\omega \mathrm{t}} \\
\mathrm{T}_{\mathrm{t}}=\frac{.49345 * 10^{6}}{1.23}=0.4 * 10^{6} \mathrm{Nm}
\end{gathered}
$$

It should be noticed that the torque should be denoted as a negative value to operate the PMSM in the generator mode. The q-axis current in steady state is calculated and given below, according to the equation 8 assuming that the mechanical torque is equivalent to the electromagnetic torque.

$$
\mathrm{iq}=\frac{-0.4 * 10^{6}}{1.5 * 44 * 1.48 * \sqrt{2}}=-2,895.7 \mathrm{~A}
$$

The steady state simulation results of the generator mechanical speed, q-axis current, electromagnetic torque, and the generated electrical power are compared with the calculated values of the system at steady state and they correspond very well to their calculated values, except that the generated electrical power is slightly smaller than the mechanical input power of the system. This is due to the internal power losses in the system. Based on the analysis above, the control objectives for the low wind speed range were achieved and the optimal power is captured and transformed by the PMSG.

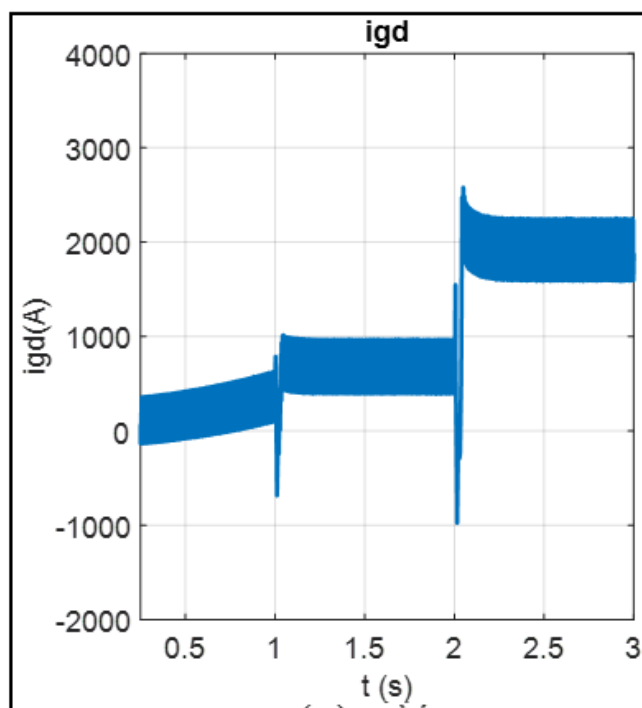

(a)

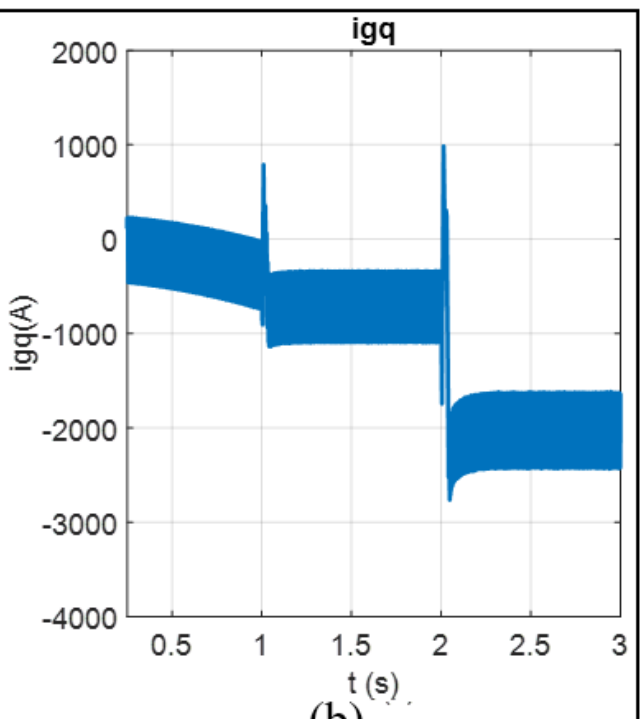

(b)

Figure 10. (a) d-axis grid current; and (b) q-axis grid current. 


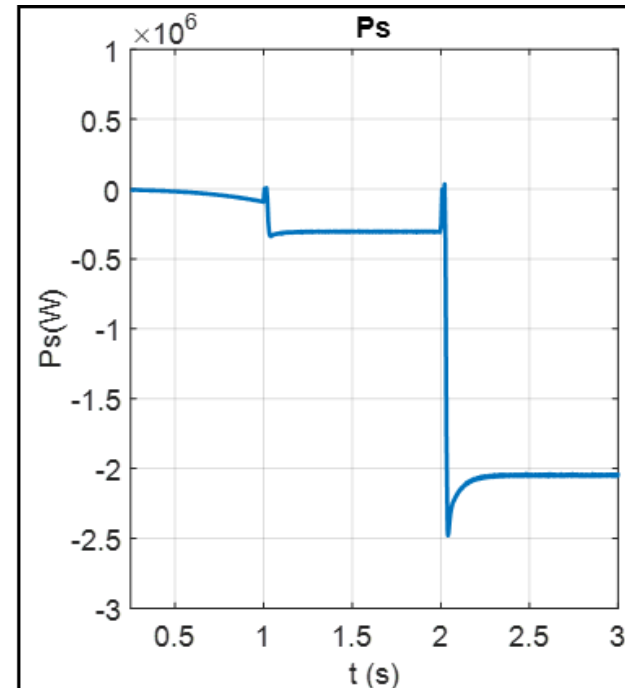

(a)

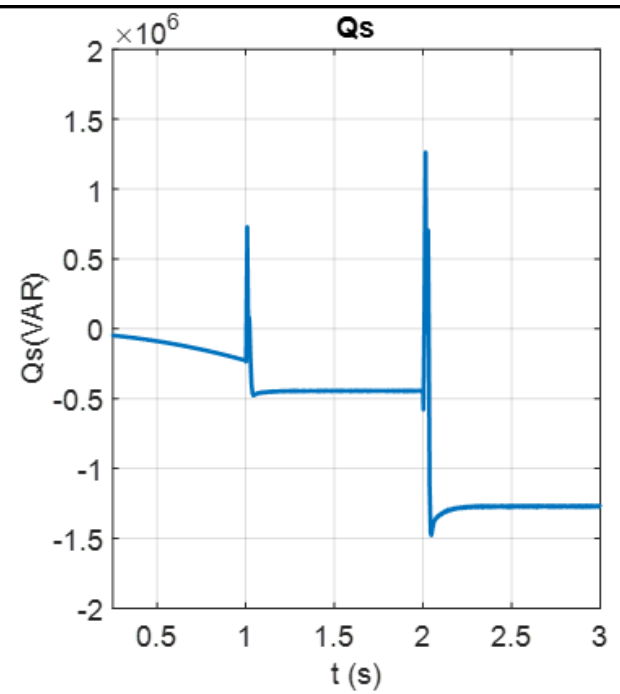

(b)

Figure 11. (a) Active power of the stator; and (b) reactive power of the stator.

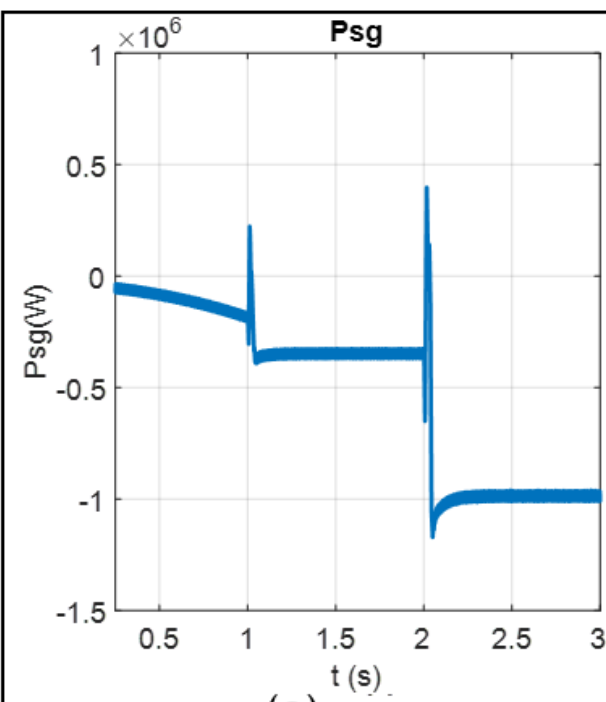

(a)

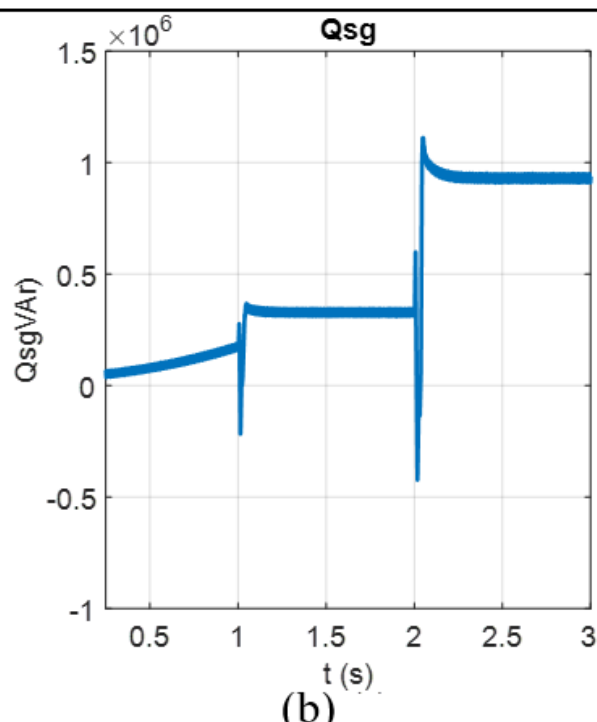

(b)

Figure 12. (a) Active power of the grid; and (b) reactive power of the grid.

Figures 9 to 12 show the results of the grid side controller dc-link voltage, dq0-axis currents of the grid and active and reactive power of the grid. As shown in figure 10, the dclink voltage is regulated very well with a very small fluctuation, which means that the active power generated by the wind turbine is transmitted to the grid smoothly. This smooth flow of active and reactive power from the stator to the grid and from the grid to the stator is clearly shown in figures 11 and 12. 


\section{CONCLUSION AND RECOMMENDATIONS FOR FUTURE WORK}

Modeling and simulation results of a grid connected PMSG-based wind turbine system is analyzed using MATLAB/SIMULINK user defined tools. Step-up at different wind velocities are considered as an input to study the performance of the model. Detailed modeling and control strategy of a DC/AC converters connected to a utility grid have been considered. The machine side converter regulated the speed control very well and the MPPT was achieved. Moreover, the inverter regulates the dc-link voltage and injected active power by d-axis current and regulates the injected reactive power by q-axis current using simple PQ control method. The reactive power required by the wind turbine is satisfied by the grid. Simulation results show that the proposed method operates satisfactorily. The results of this study is only related to the performance of a WTG in an operating wind farm. However, dip and swell in voltage are common problems due to the weak grid system. So, the performance of a WTG under different kind of faults on the wind farm to optimize the energy obtained from this wind farms should be considered as a recommendation for the future work.

\section{ACKNOWLEDGEMENTS}

The author wishes to thank, Ethiopian Institute of Technology-Mekelle, Institute of Electric Energy Systems, Otto Von Guerike University (Magdeburg, Germany) for giving us the opportunity to prepare the design and Modeling of PMSG based WTG of Adama Wind Farm 1. Moreover, DAAD and Ministry of Education for the financial support. Indeed, without their help, this article would have not been written.

\section{CONFLICT OF INTERESTS}

No conflict of interests.

\section{REFERENCE}

Abad, G. 2016. Power Electronics and Electric Drives for Traction Applications. 1st Edition, ISBN: 978-1-118-95442-3, John Wiley \& Sons Ltd, 648p.

Abad, G., Lopez, J., Rodriguez, M., Marroyo, L \& Iwanski, G. 2011. Doubly Fed Induction Machine: Modeling and Control for Wind Energy Generation. John Wiley \& Sons, ISBN: 978-0-470-76865-5, 625p.

Abu-Rub, H., Atif, I \& Jaroslaw, G. 2012. High-Performance Control of AC Drives with MATLAB/Simulink Models. John Wiley \& Sons, 482p (DOI: 10.1002/9781119969242). 
Abu-Rub, H., Mariusz, M \& Kamal Al-Haddad. 2014. Power Electronics for Renewable Energy Systems, Transportation and Industrial Applications. John Wiley \&Sons Ltd, ISBN: 978-1-118-63403-5, 826p.

Ackermann, T. 2012. Wind Power in Power Systems. ISBN: 978-0-470-97416-2, John Wiley \& Sons, 1120p.

Berhanu, M., Mekonnen, Y., Leidhold, R., Mamo, M., Muluneh, Z \& Sarwat, A. 2018. Analysis of a Doubly Fed Induction Generator through Modeling and Simulation. In Conference, 2018 IEEE PES/IAS Power Africa, IEEE, pp.652-657 (doi: 10.1109/PowerAfrica.2018.8521094).

Deng, F., Liu, D., Chen, Z \& Su, P. 2017. Control strategy of wind turbine based on permanent magnet synchronous generator and energy storage for stand-alone systems. Chinese Journal of Electrical Engineering, 3(1): 51-62 (doi: 10.23919/CJEE.2017.7961322).

Ethiopian Electric Power. 2020. Ethiopian Energy Situation. Energypedia http://www.eep.gov.et. (accessed May 25, 2020).

Franklin, G. F., Powell, J.D \& Emami-Naeini, A. 2009. Feedback Control of Dynamic Systems. $6^{\text {th }}$ edition, Pearson, ISBN-10: 0136019692, 819p.

Jayalakshmi, N. S., Gaonkar, D. N \& Sai Kiran Kumar, K. 2012. Dynamic Modeling and Performance Analysis of Grid Connected PMSG based Variable Speed Wind Turbines With Simple Power Conditioning System. In: PEDES 2012 - IEEE International Conference on Power Electronics, Drives and Energy Systems [6484474], Bengaluru, India, https://doi.org/10.1109/PEDES.2012.6484474,.

Krause, Paul C., Wasynczuk, O., Sudhoff, S.D \& Pekarek, S.D. 2013. Analysis of Electric Machinery and Drive Systems. $3^{\text {rd }}$ Edition, ISBN: 978-1-118-02429-4, Wiley-IEEE Press, 680p.

Monica, C., Santiago, A \& Juan, C. B. 2006. Control of Permanent-Magnet Generators Applied to Variable-Speed Wind Energy Systems Connected to the Grid. IEEE Transactions on Energy Conversion, 21(1): 130-135.

Orlando, N.A., Liserre, M., Mastromauro, R.A \& Dell'Aquila, A. 2013. A Survey of Control Issues in PMSG-Based Small Wind-Turbine Systems. IEEE Transactions on Industrial Informatics, 9(3): 1211-1221 (doi: 10.1109/TII.2013.2272888).

Polinder, H., Ferreira, J.A., Jensen, B.B., Abrahamsen, A.B., Atallah, K \& McMahon, R.A. 2013. Trends in Wind Turbine Generator Systems. IEEE J. of Emerging and Selected Topics in Power Electronics, 1(3): 174-185, doi: 10.1109/JESTPE.2013.2280428. 
Teodorescu, R., Liserre, M \& Rodriguez, P. 2011. Grid Converters for Photovoltaic and Wind Power Systems. ISBN: 978-0-470-05751-3, Wiley-IEEE Press, 416p.

Wu, B., Lang, Y., Zargari, N \& Kouro, S. 2011. Power Conversion and Control of Wind Energy Systems. ISBN: 978-0-470-59365-3, Wiley-IEEE Press, 480p.

Yaramasu, V \& Wu, B. 2014. Predictive Control of a Three-Level Boost Converter and an NPC Inverter for High-Power PMSG-Based Medium Voltage Wind Energy Conversion Systems. IEEE Transactions on Power Electronics, 29: 5308-5322 (doi:10.1109/TPEL.2013.2292068).

Zenachew, M. H., Leidhold, R \& Gebremichael, T. T. 2019a. Real-Time Power Control of a Permanent Magnet Synchronous Generator Based Wind Turbine through a Laboratory Test-Rig. 2019 IEEE PES/IAS Power Africa, pp.368-373 (doi: 10.1109/PowerAfrica.2019.8928659).

Zenachew, M. H., Leidhold, R \& Gebremichael, T. T. 2019b. Real-Time Speed Control of a PMSM for Wind Turbine Application. 2019 IEEE PES/IAS Power Africa, 2019, pp. 396-401, doi: 10.1109/PowerAfrica.2019.8928919. 
Appendix 1. Wind turbine data.

\begin{tabular}{|l|l|}
\hline WTG Version & $\boldsymbol{G W} \mathbf{1 . 5 / 7 7}$ \\
\hline Wind turbine nominal power $(\mathrm{MW})$ & 1.5 \\
\hline Number of wind turbines & 34 \\
\hline Wind turbine inertia constant $(\mathrm{H}(\mathrm{s}))$ & 4.32 \\
\hline Rotor diameter $(\mathrm{m})$ & 77 \\
\hline Wind turbine rotor radius $(\mathrm{m})$ & 37.3 \\
\hline Tower height $(\mathrm{m})$ & 65 \\
\hline Cut-in wind speed & $3 \mathrm{~m} / \mathrm{s}$ \\
\hline Rated wind speed & $11 \mathrm{~m} / \mathrm{s}$ \\
\hline Optimal speed ratio $\left(\lambda_{\mathrm{opt}}\right)$ & 6.14 \\
\hline Maximum Power coefficient $\left(\mathrm{C}_{\mathrm{p}, \mathrm{max}}\right)$ & 0.45 \\
\hline Cut-out wind speed & $22 \mathrm{~m} / \mathrm{s}$ \\
\hline Swept area & $4649 \mathrm{~m}^{2}$ \\
\hline Number of blades & 3 \\
\hline Power control & Collective pitch control/rotor speed control \\
\hline
\end{tabular}

Appendix 2. Generator data.

\begin{tabular}{|l|l|}
\hline Generator Type & $P M S G, 1.5 M W, 620 \mathrm{~V}, 12.7 \mathrm{~Hz}$, multi-pole (non-salient pole) \\
\hline Rated Mechanical Power & $1.5 \mathrm{MW}$ \\
\hline Rated Apparent Power & $1.6 \mathrm{MVA}$ \\
\hline Generator inertia & $35000\left(\mathrm{~J} / \mathrm{kg} \cdot \mathrm{m}^{2}\right)$ ) \\
\hline Rated Power Factor & 0.97 \\
\hline Speed Range & $9-17.3 \mathrm{rpm}$ \\
\hline Rated speed & 17.3 \\
\hline Shaft stiffness $(\mathrm{pu})$ & 0.3 \\
\hline Number of Pole Pairs & 44 \\
\hline Rated Rotor Flux Linkage & 1.48 \\
\hline Stator Winding Resistance & $0.006 \Omega$ \\
\hline d axis Synchronous Inductance & $0.395 \mathrm{mH}$ \\
\hline q axis Synchronous Inductance & $0.395 \mathrm{mH}$ \\
\hline Rated current & $680 \mathrm{~A}$ \\
\hline Static friction & 0.01 \\
\hline Viscous damping & 1.5 \\
\hline
\end{tabular}

